\title{
Ecological, Economic and Social Development Evaluation of Wuling Mountain Area Using Entropy Method
}

\author{
Weijun $\mathrm{He}^{1, \mathrm{a}}$ Miao Yang ${ }^{2, \mathrm{~b}}$ Liang Yuan ${ }^{3, \mathrm{c}}$ \\ ${ }^{1,2}$ Economics and Management College, China Three Gorges University ,Yichang 443002,China; \\ ${ }^{3}$ Business College, HohaiUniversity,Nanjing 210000,China \\ a7292309@qq.com, ${ }^{b} 377344602 @ q q . c o m,{ }^{c}$ gooleyvette@gmail.com
}

\section{Keywords: Wuling mountain area; Ecological economic; Entropy}

\begin{abstract}
In today's china, imbalance between ecological protection and economic development a common phenomenon. This research paper by constructing the Eco economic evaluation index using the entropy method analyzed the eco-economic development of the Hunan Wuling Mountain Area by selecting 25 counties and districts in the area.The evaluation result showed the imbalance between economic development and environmental protection in the selected areas.In addition the study identified the area's ecological problems as the result of the growing economy. Finally mechanisms and policy recommendations that should be taken in to account to mitigate this imbalance and put the region in a sustainable growth path were forwarded.
\end{abstract}

\section{Introduction}

Nowadays we are witnessing the emergence of environmental problems with economic development and they are becoming a focus of attention. Wuling Mountain Area is one of the areas with poor economic development where poverty alleviation is the main challenge ${ }^{[1]}$. The area is one of the demonstration areas selected by the government for poverty alleviation 2014. But as the economic development of the area starts to grow the problem of increased environmental deteriorationstarted to prevail ${ }^{[2]}$. Asresult the question of coordination environmental protecting and economic development has become a research topic for many researchersthese days. Therefore, this study aims to identify the area's ecological problems as the result of the growing economy and propose measures that will guide the economic development of the area in to a sustainable path.

\section{Methodology}

The study selected 25 countries and districts in Hunan Wuling Mountain Area based on geographical distribution and data reliability forsampling. A more objective evaluation and analysis of the selected indicators were done using the entropy method. TheEcological and economy comprehensive evaluation index system was built to provide a scientific basis for policy-making for building ecological sustainability. By considering the economic social and environmental characteristics of the Hunan Wuling Mountain Area the following index was built. Thenusing the entropy method of the original matrix was constructed and the data was normalized. Then entropy of the selected 16 indicators was calculated, resulting in 16 utility value indicators or index weights. Finally the weighted sum of each used to calculate the scores for each of the 25 areas. This evaluation index is scientific, systematic, comprehensive and practical.

\section{Results and Discussion}

The results obtained using the built evaluation index for evaluating the eco-economicdevelopment level of the Wuling Mountain Area counties are shown in the graph below. 


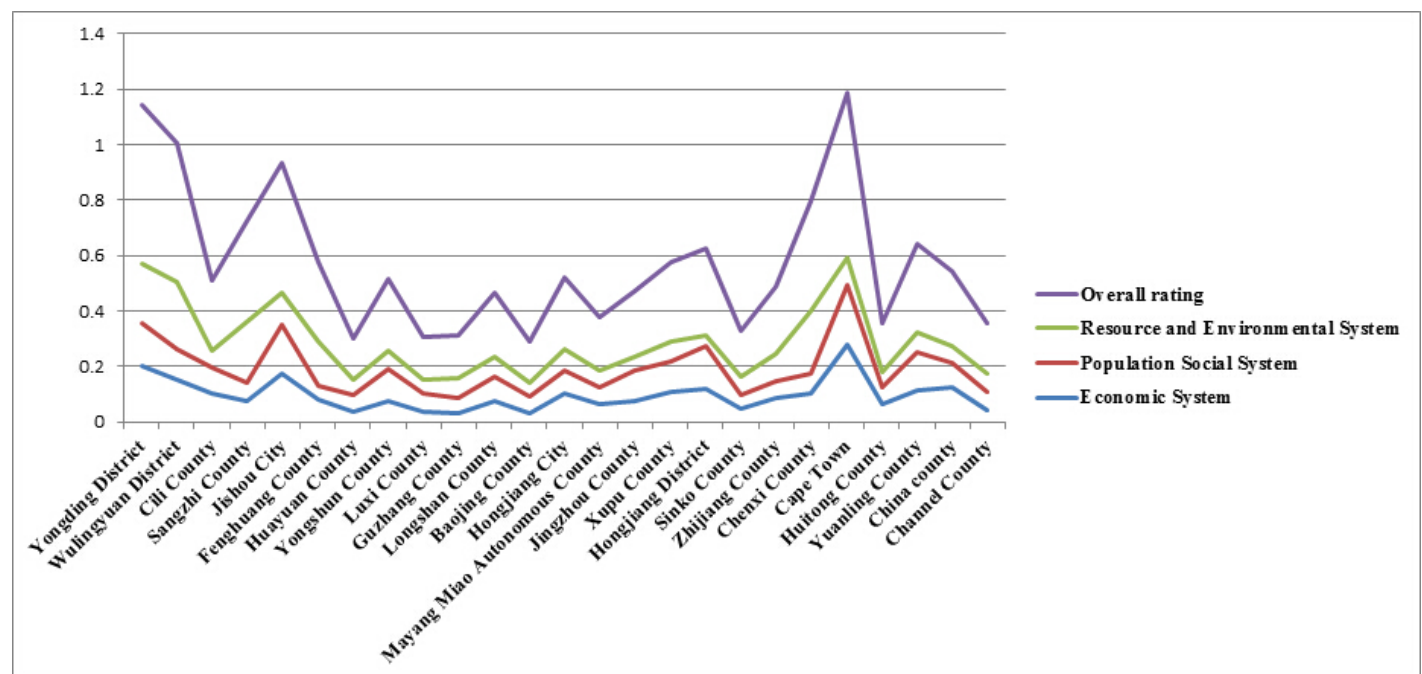

Graph1: Hunan Wuling Mountain Area 25 counties (cities, districts) development level of ecological and economic score and ranking

Wuling Mountain Area is one of the 18 poverty-stricken areas; it includes 71 counties (cities, districts) in Hubei, Hunan, Guizhou, and Chongqing. The ecological environment of the area is under extremely fragile state. Ecological Economy lags far behind other developed regions. The results show that Zhangjiajie, HuaihuaXiangxi and, for example are under rapid economic development while other are not. This shows that the Wuling Mountain Area's regional eco-economic development is uneven. Health care, education, nature conservation in the area are rapidly developing ${ }^{[3]}$. Despite the economic system and social system, boosting the ecological comprehensive population development index rose, but the construction of the natural ecology is still long way to $\mathrm{go}^{[4]}$.The following section describes the main reason for the imbalance and developmental differences between the different cities and counties in the area.

The results showed that the level of overall ecological development in Zhangjiajie City was significantly higher than the other regions, which shows the city of Zhangjiajie in the economic, social and environmental resources have certain development advantages. From the overall score, the top three highest scores are for Cape Town, Yongding District and Wulingyuan District. This is because the Yongding District and Cape Town respectively like Zhangjiajie and Huaihua, these cities have financial and material agglomeration advantages, coupled with highly concentrated population, complete infrastructure, high urbanization, relatively developed industry.

Areas which are far away from the center have less score and ranked lower. Table 3 demonstrates the theory of urban growth proposed by ${ }^{[5]}$ the furthest from the centerthe weaker the economy taking the scores of the four counties namely Jishou, Fenghuang, HuayuanBaojing and Baojing.

Table.1: Comparison of Jishou, Fenghuang, Huayuan,Baojing and Baojingusing eco-economic evaluation index

\begin{tabular}{|c|c|c|c|c|}
\hline & Jishou City & Fenghuang County & Huayuan County & Baojing County \\
\hline $\begin{array}{c}\text { Straight-line distance } \\
\text { from the Xiangxi }\end{array}$ & $0 \mathrm{~km}$ & $36.7 \mathrm{~km}$ & $40.3 \mathrm{~km}$ & $49.4 \mathrm{~km}$ \\
\hline Composite score & 0.4662 & 0.2894 & 0.1511 & 0.1439 \\
\hline ranking & 4 & 9 & 24 & 25 \\
\hline
\end{tabular}




\section{Conclusion}

In the economic system development, the Hunan Wuling Mountain Area's are experiencing rapid economic development, particularly in the city of Zhangjiajie, HuaihuaXiangxi Autonomous. But economic development is not the only measure of development social and environmental developments also should be included. Development of the population is a sign of ecological social systems and economic development. Ecological economic development is inseparable from social progress. Hunan Wuling Mountain Area in the rapid economic development process is ignoring the eco-economy development. As the result higher quality of social development is only concentrated in and around the main cities. Wuling Mountain Area is rich in natural resources. However, due to the pursuit of economic growth, one-sided industrial development, ignoring the tertiary industry and environmental protection, thus an ecological situation worse, so the need to constantly optimize economic development and environmental protection in order to assure the sustainable development of the area.

\section{Recommendation}

After analyzing the economic, social and environmental situation of economic of Wuling Mountain Area, theauthors recommend the following to minimize and the developmental imbalance between the environmental economic and social status in the region.

Formulate a green GDP performance evaluation system.

Improve the ecological compensation mechanism by playing the role of government.

To develop ecological industries, strengthening industrial clusters.

Develop transportationinfrastructure, improve the level of urbanization.

Develop education and enhance awareness of energy saving.

Generally from the Overall through study of the Hunan Wuling Mountain Area the authorsbelieve that the area has huge potential for development. If the economic and environmental development efforts are coordinated the growth of the region will be much faster and sustainable.

\section{Acknowledgments}

This study stems from The Project (No.13BMZ057) supported by National Social Science Fund .The authors would like to express their deepest gratitude for the support. The authors also would like to thank Dagmawi Mulugeta Degefu for his assistance during the course of the study.

\section{References}

[1] Helen Suich, Caroline Howe. Ecosystem services and poverty alleviation: A reviewof the empirical links. Ecosystem Services.12(2015)137-147.

[2] Alexandre Berthe, Luc Elie. Mechanisms explaining the impact of economic inequality o nenvironmental deterioration. Ecological Economics.116(2015) 191-200.

[3] Anne MarikeLokhorst ,CélineHoon. There is an I in nature: The crucial role of the self in natureconservation. Land Use Policy.39(2014) 121-126

[4]Cao Hui. Evaluation of Ecological Economy in Minority Areas Based on Entropy [J]. G uizhou Ethnic Studies.35(2014) 81-85.

[5]Noboru Sakashita. An economic theory of urban growth control. Regional Science and U rban Economics.25(1995) 427-434. 